\title{
Quasi - 3D and Full - 3D Approaches for Numerical Simulation in Axial Flow Hydraulic Turbine
}

\author{
Vishnu Prasad, K.S. Sayann, Prof P. Krishnamachar
}

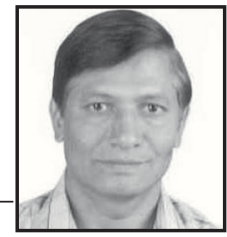

Vishnu Prasad

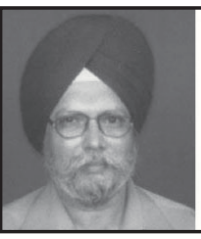

KS Sayann

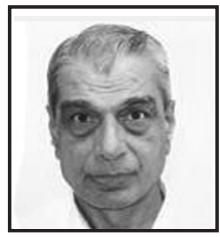

P Krishnamachar

\begin{abstract}
Water passes through the rows of stationary and rotating blades in the turbine space and thus the flow becomes complex. The application of computational fluid dynamics (CFD) is steadily increasing to improve design of hydraulic turbines. The numerical flow simulation in the hydraulic turbine space can either be based on potential or viscous flow theory. In both the approaches, detailed flow behavior in complete turbine space is obtained. The quasi3D potential flow approach is quick and simple as compared to full-3D viscous flow methods of analysis but do not take into account the friction losses, which need to be computed separately. The direct flow analysis has been carried out in an experimentally tested model of axial flow hydraulic turbine using the two approaches and the comparison of flow pattern and computed parameters in runner is made in present paper. The computed efficiencies and other performance parameters have also been compared with experimental values at some critical points for validation.
\end{abstract}

Key words: Hydraulic turbine, computational fluid dynamics, meridional flow, circulation.

\section{Nomenclature}

C - absolute velocity $(\mathrm{m} / \mathrm{s})$

$\mathrm{C}_{\mathrm{M}} \quad$ - meridional velocity $(\mathrm{m} / \mathrm{s})$

$\mathrm{C}_{\mathrm{U}} \quad$ - whirl velocity $(\mathrm{m} / \mathrm{s})$

D - diameter of turbine runner (m)

g - gravitational acceleration $\left(\mathrm{m} / \mathrm{s}^{2}\right)$

h $\quad$ - specific pressure energy $\left(\mathrm{m}^{2} / \mathrm{s}^{2}\right)$

$h_{t} \quad$ - total specific energy $\left(\mathrm{m}^{2} / \mathrm{s}^{2}\right)$

$\mathrm{H}_{\mathrm{S}} \quad$ - shock loss at inlet of runner in quasi-3D flow $(\mathrm{m})$

n $\quad$ - rotational speed of runner (rpm)

Q - discharge through turbine $\left(\mathrm{m}^{3} / \mathrm{s}\right)$

$\mathrm{T}$ - torque on runner blade $(\mathrm{N}-\mathrm{m})$

$\mathrm{t} \quad$ - pitch of runner blades (m)

$\mathrm{TP}_{\mathrm{SVI}} \quad$ - total pressure at stay vane inlet $(\mathrm{Pa})$

$\underline{\mathrm{TP}}_{\text {DTE }} \quad$-total pressure at draft tube outlet (Pa)

$\overline{\mathrm{u}} \quad$ - mean velocity $(\mathrm{m} / \mathrm{s})$

$\mathrm{u}^{\prime} \quad$ - fluctuating velocity components $(\mathrm{m} / \mathrm{s})$

U - peripheral velocity of runner tip $(\mathrm{m} / \mathrm{s})$

W - relative velocity $(\mathrm{m} / \mathrm{s})$

$\omega \quad$ - angular velocity of runner $(\mathrm{rad} / \mathrm{s})$

$\rho \quad-$ mass density of water $\left(\mathrm{kg} / \mathrm{m}^{3}\right)$

$\beta \quad$ - flow angle from tangential direction $\left({ }^{\circ}\right)$

$\gamma \quad$ - specific weight of water $\left(\mathrm{N} / \mathrm{m}^{3}\right)$

\section{Subscripts}

1 at inlet of runner

2 at outlet of runner

\section{Introduction}

T The flow in hydraulic reaction turbines is complex and it varies from hub to tip due to interaction of flow between blade rows. Further, the flow conditions are also changed due to opening of guide vanes and geometrical configuration of runner blades. Energy is transferred from water to runner due to provision of varying stagger and camber at different sections of blades. In axial flow turbine, water comes out of runner with significant amount of kinetic energy and it is partially recovered in draft tube. Hence draft tube also plays important role in the performance of axial flow turbines (Csanady 1964; Nechleba 1957). In the analysis of flow through runner blades by direct or indirect method of runner design, flow is generally taken as steady. The direct method is generally used for flow analysis in existing or designed turbines. The comparison of velocity and pressure distribution for the runner between hub and tip is obtained by two numerical approaches viz two dimensional and three-dimensional inviscid flow (Daniel, Romeo and Sebastian 2003:29-36). In quasi-3D potential flow analysis, the three-dimensional flow is divided into two two-dimensional flow problems: meridional flow and bladeto-blade analysis for blade rows, and it is much simpler and computationally quicker as compared to full-3D viscid flow approach. Hence it is proposed to use quasi-3D for initial design based on indirect method and then to apply full-3D viscous flow method for final design (Peng, Cao, Ishizuka and Shinji Hayama 2002:533-54). The three- dimensional analysis is used for optimum design of hydraulic turbines (Liplej 2004:43-50; Peng 2005:1183-1190).

As one blade row affects the flow pattern at other blade row, numerical analysis of individual blade row has the problem of defining proper boundary condition because of unknown flow behavior at upstream and downstream of any particular blade row. With development of high computational speed and memory, this problem is overcome by carrying out combined flow analysis through all blade rows simultaneously.

In the present paper, quasi-3D potential flow and full-3D viscous flow analyses have been made of axial flow turbine consisting of stay ring, distributor, runner and draft tube for three operating regimes by MIXFLO and Ansys CFX10.0 commercial codes. The computed non-dimensional flow parameters from both approaches are presented in tabular 
and graphical form and critically compared.

\section{Definition of geometry}

The specification of geometry for complete flow space is one of the important input data for any numerical simulation. All the three blade rows of the turbine are axi-symmetric. The axial flow turbine model being analyzed has 12 stay vanes, 28 guide vanes and four runner blades. The diameter of turbine model runner is $400 \mathrm{~mm}$. The geometry input for quasi-3D method is much simple as compared to full-3D analysis. The grid coordinates $(\mathrm{x}, \mathrm{r})$ are given within the twodimensional meridional space with three blade rows on one side of the axis of rotation for quasi-3D analysis. The twodimensional meridional space with locations of stay vane, guide vane and runner is shown in figure1. The draft tube is not considered in this analysis and head recovery in it is computed using empirical formula obtained by regression. The space between the hub and casing is divided into 10 sections and blade profile coordinates at all 10 sections of blade are given for each blade row.

The space from inlet to outlet is divided into 50 cells. The software can either accept $(\mathrm{r}, \theta, \mathrm{z})$ coordinates for existing

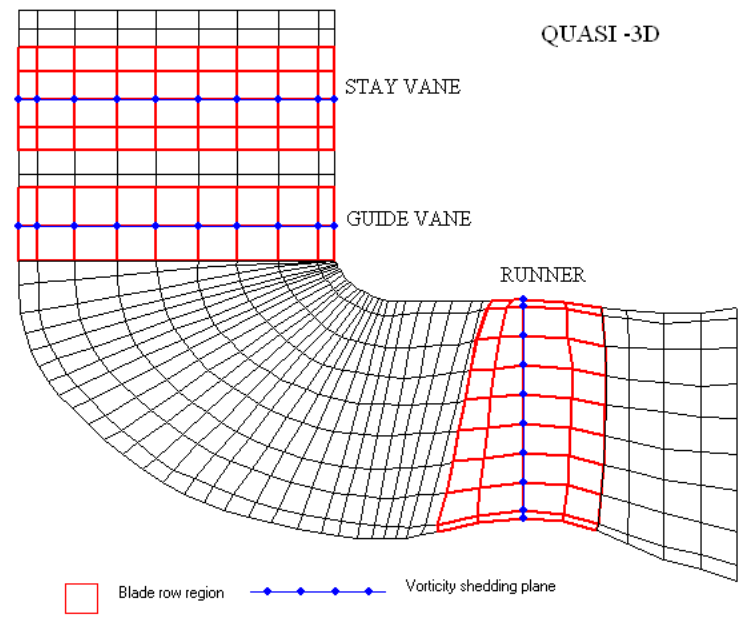

Fig 1: Two-dimensional space geometry for quasi-3D analysis

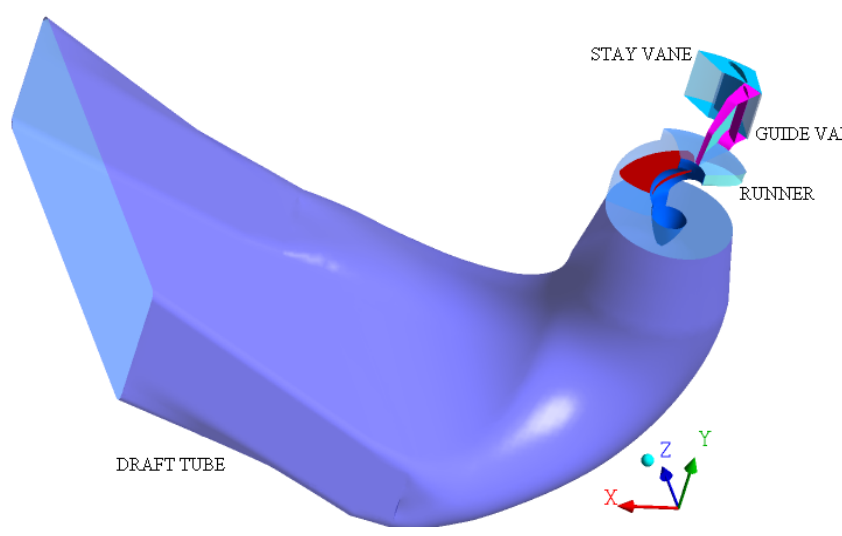

Fig 2: Three-dimensional geometry for full-3D analysis blades or blade cascade data for new design. The supplement programs are developed in FORTRAN to generate data for different configurations of guide vane and runner blade profiles.

In case of full-3D viscous flow analysis, $3 \mathrm{D}$ geometric modeling for stay vane, guide vane, runner and draft tube is carried out separately and then assembled through proper interfaces to form complete flow domain. A single blade from each blade row is modeled for numerical simulation, because of axi-symmetry, by providing the rotational periodicity for stay vane, guide vane and runner. This has minimized the total size of mesh elements and nodes. The draft tube is fully modeled because of no symmetry about any axis. The assembled three-dimensional geometry is shown in figure 2. The unstructured tetrahedral mesh has been used for meshing of flow domain. The summary of nodes and elements in mesh for each domain is given in Table 1 . The change in guide vane opening is achieved by modeling this component separately for three openings. All other components such as stay vanes, runner for the chosen blade angle and draft tube remain the same and are assembled with changed guide vanes to develop the complete three-dimensional model for analysis at different operating regimes.

\section{Boundary conditions}

The results obtained from the numerical simulation in any flow domain depend on the specified boundary conditions. In case of quasi-3D potential flow analysis, total flow rate with flow direction is specified at stay vane inlet as inlet boundary condition and rotational speed for each blade row. The assumed flow angles or whirl velocities at outlet of each blade row are specified as outlet boundary condition. These get modified during the iteration process between meridional and blade-to-blade analysis.

In full-3D viscous flow, total mass flow is divided by number of stay vane passages and the mass flow rate along with direction through passage between two stay vanes is specified at stay vane inlet as inlet boundary condition. The static reference pressure at the outlet of the draft tube is specified equal to zero as outlet boundary condition. The

\begin{tabular}{|c|c|c|}
\hline Domain & No. of nodes & No. of elements \\
\hline Stay vane & 24811 & 126527 \\
\hline Guide vane & 15563 & 71275 \\
\hline Runner & 25267 & 130868 \\
\hline Draft tube & 279151 & 1540907 \\
\hline
\end{tabular}

Table 1: Summery of mesh data

\begin{tabular}{|l|r|r|r|}
\hline Guide vane opening & $\alpha=35^{\circ}$ & $\alpha=40^{\circ}$ & $\alpha=50^{\circ}$ \\
\hline $\begin{array}{l}\text { Discharge }\left(\mathrm{m}^{3} / \mathrm{s}\right) \text { for } \\
\text { both approach }\end{array}$ & 0.620 & 0.570 & 0.714 \\
\hline $\begin{array}{l}\text { Rotational speed (rpm) } \\
\text { for full-3D }\end{array}$ & 1260 & 1155 & 1440 \\
\hline $\begin{array}{l}\text { Rotational speed (rpm) } \\
\text { for quasi-3D }\end{array}$ & 1219 & 1131 & 1426 \\
\hline
\end{tabular}

Table 2: Input data for numerical simulation 
distribution of mass flow for each blade row is automatically done at interfaces depending on pitch change between domains. The stay vane, guide vane and draft tube domains are set stationary and the rotational speed of runner is specified. The values of discharge and rotational speed for different guide vane openings are given in Table 2.

\section{Governing equations and numerical method}

The three-dimensional turbulent flow is represented by Reynolds Averaged Navier Stokes (RANS) equations (Ansys CFX 2005), consisting of continuity, momentum and energy equations. These equations are given as:

Continuity $\frac{\partial \rho}{\partial \mathrm{t}}+\nabla \square(\rho \overline{\mathrm{u}})=0$

Momentum $\frac{\partial(\rho \bar{u})}{\partial \mathrm{t}}+\nabla \square(\rho \overline{\mathrm{u}} \otimes \overline{\mathrm{u}})=\nabla \square\left(\tau-\rho \overline{\mathrm{u}^{\prime} \otimes \mathrm{u}^{\prime}}+\mathrm{S}_{\mathrm{M}}\right.$

Energy $\quad \frac{\partial\left(\rho h_{t}\right)}{\partial t}+\nabla \llbracket\left(\rho \overline{u h}_{t}+\rho \overline{u^{\prime} h}-\lambda \nabla \tau\right)=\frac{\partial p}{\partial t}$

These equations are non-linear and their analytical solution is not possible and hence approximate solution is obtained by numerical methods. Additional sources of momentum are required for flow in rotating frame of reference like runner, to account for the effect of coriolis and centrifugal forces and are given as

$\mathrm{S}_{\mathrm{COR}}=-2 \rho \omega \times \mathrm{U}$

$\mathrm{S}_{\mathrm{CF}}=-\rho \omega \times(\omega \times \mathrm{r})$

and energy equation, total specific energy is modified as

$\mathrm{h}_{\mathrm{t}}=\mathrm{h}_{\mathrm{stat}}+\frac{1}{2} \overline{\mathrm{u}}_{\mathrm{r}}^{2}-\frac{1}{2} \omega^{2} \mathrm{r}^{2}$

The numerical solution of RANS equations for steady state viscous turbulent flow is carried out in hydraulic turbine with SST $\kappa-\omega$ turbulence model by Ansys CFX10.o software. The finite volume method is used for discretization of RANS equations. The mesh generated in Ansys ICEM CFD10.o is checked for mesh quality parameters. The $\mathrm{y}^{+}$varies between 24 to186 for three blade rows which is the acceptable range for automatic wall function treatment in boundary layer. Further modification of mesh near boundaries for decreasing value of $\mathrm{y}^{+}$is not considered necessary as the objective of full-3D analysis is to validate results of quasi-3D analysis.

In quasi-3D approach, first grid is generated in twodimensional meridional space and its coordinates are given as geometry input. Stoke's equation in terms of stream function for meridional flow and Martensen's equation for blade-to-blade flow are given below:

Stokes' Equation: $\frac{\partial \varnothing^{2}}{\partial \mathrm{z}^{2}}-\frac{1}{\mathrm{r}} \frac{\partial \varnothing}{\partial \mathrm{r}}+\frac{\partial \varnothing^{2}}{\partial \mathrm{r}^{2}}=-\grave{\mathrm{u}}_{\mathrm{e}} \mathrm{r}$

Martensens' equation:

where,

$-\frac{1}{2} \gamma\left(s_{m}\right)+\int k\left(s_{m}, s_{n}\right) \gamma\left(s_{n}\right) d s_{n}+V_{m}\left(\operatorname{Cos} \chi_{m} \operatorname{Cos} \varphi_{m}+\sin \chi_{m} \operatorname{Sin} \varphi_{m}\right)=0$

$\mathrm{k}\left(\mathrm{s}_{\mathrm{m}}, \mathrm{s}_{\mathrm{n}}\right)=\frac{1}{2 \pi}\left\{\frac{\left(\mathrm{y}_{\mathrm{m}}-\mathrm{y}_{\mathrm{n}}\right) \operatorname{Cos} \beta_{\mathrm{m}}-\left(\mathrm{x}_{\mathrm{m}}-\mathrm{x}_{\mathrm{n}}\right) \operatorname{Sin} \beta_{\mathrm{m}}}{\left(\mathrm{x}_{\mathrm{m}}-\mathrm{x}_{\mathrm{n}}\right)^{2}+\left(\mathrm{y}_{\mathrm{m}}-\mathrm{y}_{\mathrm{n}}\right)^{2}}\right\}$

These equations are solved by surface boundary integral in MIXFLO software (Lewis 1996). This software is exclusively for analysis of potential flow in turbo-machines. The numerical solution of governing equations in both approaches gives values of pressure and velocity at element nodes. The required parameters are computed from the above pressure and velocity distribution by developing program in FORTRAN.

\section{Computation of non-dimensional parameters}

The non-dimensional flow parameters are computed using the following expressions:

Total head for quasi-3D flow

$$
\mathrm{H}=\frac{\mathrm{C}_{\mathrm{U} 1} \mathrm{U}_{1}-\mathrm{C}_{\mathrm{U} 2} \mathrm{U}_{2}}{\mathrm{~g}}+\frac{\mathrm{C}_{2}^{2}}{2 \mathrm{~g}}+\mathrm{H}_{\mathrm{S}}
$$

Draft tube recovery coefficient

$$
v=\frac{\left(K_{M} C_{M}^{2}+K_{U} C_{U}^{2}\right)}{2 g H}
$$

Values of $\mathrm{K}_{\mathrm{M}}$ and $\mathrm{K}_{\mathrm{U}}$ are computed as (0.75, 0.25), (0.71, $0.20)$ and $(0.65,0.15)$ by regression for guide vane opening $50^{\circ}, 40^{\circ}$ and $35^{\circ}$ respectively.

Head utilized by runner in quasi-3D flow

$$
\mathrm{H}_{\mathrm{R}}=\frac{\mathrm{C}_{\mathrm{U} 1} \mathrm{U}_{1}-\mathrm{C}_{\mathrm{U} 2} \mathrm{U}_{2}}{\mathrm{~g}}+v \mathrm{H}
$$

Total head in full-3D analysis

$$
\mathrm{H}=\frac{\mathrm{TP}_{\mathrm{SVI}}-\mathrm{TP}_{\mathrm{DTE}}}{\gamma}
$$

Head utilized by turbine in full-3D analysis

$$
\mathrm{H}_{\mathrm{R}}=\frac{\pi \mathrm{nT}}{60 \gamma \mathrm{Q}}
$$

\section{Validation of numerical results}

The numerical simulation of flow is based on the approximate solution of governing partial differential equations and accuracy of solution depends on many factors. Hence, it is necessary to validate the results from numerical 
Specific meridional velocity

$\mathrm{c}_{\mathrm{m}}=\frac{\mathrm{C}_{\mathrm{M}}}{\sqrt{2 \mathrm{gH}}}$

Specific whirl velocity

$c_{u}=\frac{\mathrm{C}_{\mathrm{U}}}{\sqrt{2 \mathrm{gH}}}$

Specific relative velocity

$\mathrm{w}=\frac{\mathrm{W}}{\sqrt{2 \mathrm{gH}}}$

Degree of reaction

$\varphi=\frac{\mathrm{W}_{2}^{2}-\mathrm{W}_{1}^{2}}{2 \mathrm{gH}}$

Flow deflection

$\varepsilon=\beta_{1}-\beta_{2}$

Blade circulation coefficient

$\tau=\frac{\mathrm{t}\left(\mathrm{C}_{\mathrm{U} 1}-\mathrm{C}_{\mathrm{U} 2}\right)}{\mathrm{D} \sqrt{2 \mathrm{gH}}}$

Specific energy coefficient

$\psi=\frac{\mathrm{gHD}^{4}}{\mathrm{Q}^{2}}$

Speed factor

$\mathrm{SF}=\frac{\mathrm{nD}}{\sqrt{\mathrm{gH}}}$

Discharge factor

$$
\mathrm{DF}=\frac{\mathrm{Q}}{\mathrm{D}^{2} \sqrt{\mathrm{gH}}}
$$

Hydraulic efficiency

$\eta_{\mathrm{H}}=\frac{\mathrm{H}_{\mathrm{R}}}{\mathrm{H}} * 100$

analysis with experimental results. The results from full-3D analysis are validated for different flow problems including turbines (Liplej 2004:43-50; Rao and Tripathi 2007:196201). In case of turbines, experimental results are available in terms of global design parameters of turbine i.e variation of efficiency at different regimes of operation and hence comparison of computed and experimental results is given in terms of speed, discharge and efficiency. The quasi-3D potential and full-3D viscous analyses are carried out at about maximum efficiency regimes at three guide vane openings. The values of speed factor and discharge factor at each guide vane opening are taken from experimental data and kept the same in both numerical approaches. The comparison of hydraulic efficiencies from numerical computations and experiment is given in Table 3 .

\begin{tabular}{|l|l|l|l|}
\hline Guide vane opening & $\alpha=50^{\circ}$ & $\alpha=40^{\circ}$ & $\alpha=35^{\circ}$ \\
\hline Speed factor & 55.51 & 46.57 & 42.58 \\
\hline Discharge factor & 0.430 & 0.359 & 0.327 \\
\hline Experimental efficiency (\%) & 90.86 & 92.06 & 91.59 \\
\hline $\begin{array}{l}\text { Computed efficiency (\%) } \\
\text { from full-3D approach }\end{array}$ & 90.19 & 92.24 & 89.97 \\
\hline $\begin{array}{l}\text { Computed efficiency (\%) } \\
\text { from quasi-3D approach }\end{array}$ & 92.69 & 94.26 & 93.91 \\
\hline
\end{tabular}

Table 3: Comparison of computed and experimental results

It is observed from Table- 3 that the peak efficiency regime indicated by computation in both numerical approaches and by experiment is same. The computed efficiencies from full-3D analysis at different regimes are in close agreement with experimental values. The efficiency obtained by quasi-3D approach is higher than full-3D approach because of differences in considering losses. The difference in efficiencies obtained from quasi-3D and full$3 \mathrm{D}$ analysis from experimental values may be ascribed to (i) differences in discretization of governing equations and flow domain, (ii) losses not accounted fully and precisely in CFD analysis and (iii) not considering casing in analysis.

\section{Results and discussions}

The stream-wise location for computation of velocities and other parameters can be exactly matched with leading edge (LE) and trailing edge (TE) of runner blades in quasi-3D method while in case of full-3D approach, it is not possible to match the stream wise grid line with leading edge LE and TE of runner. The specific velocities are computed by normalizing the actual velocity with the spouting velocity $\sqrt{ }(2 \mathrm{gH})$. The computed mass averaged values of velocities and other flow parameters at inlet and outlet of runner are given in Table 4. It is found that numerical values of different parameters from both the approaches are in close agreement and differ slightly due to difference in total head required for same operating regime.

The pattern of variation of meridional velocities at different guide vane openings from hub to tip also agreed reasonably well as shown in figure 3 and figure 4 .

The magnitude of these velocities at any point between hub to tip increases with guide vane opening. It is due to increase in discharge with increase in guide vane opening. The meridional velocities at inlet is maximum near mid span and decreases toward hub and tip while at outlet, it is nearly constant at all guide vane openings except hub region.

It is observed from figure 5 and figure 6 that the whirl velocities at inlet of runner decrease from hub and then slightly increased at tip while at outlet, these are increasing from hub to tip in both approaches indicating more energy extraction at hub than at the tip. The whirl velocities at 
inlet decrease with increase in guide vane opening at any span-wise location and remain sensibly same at tip. Their variation from hub to tip at outlet is nearly independent of guide vane opening.

The span-wise flow angles variation in figure 7 and figure 8 depicts that flow angles decrease from hub to tip at both inlet and outlet of runner. The flow angles at inlet are affected by guide vane opening and they increase with decrease in guide vane opening. The flow angles on tip side at inlet and from hub to tip at outlet are nearly independent of regime of turbine operation.

\section{Conclusions}

The comparison between computed and experimental efficiencies indicates that the best efficiency regime indicated by computation from both the numerical approaches and experiment is the same and the value of computed efficiency from full-3D analysis is in close agreement with the experimental value at this regime. The accuracy of computed results can be improved by making fine grids. The difference between computed efficiencies from both numerical approaches and experimental values may be ascribed to (i) differences in discretization of governing equations and flow domain, (ii) non-assessment of losses precisely in CFD analysis and (iii) casing not considered in analysis.

The full-3D analysis tackles the flow behavior in better way than quasi-3D analysis but the geometrical modeling for this analysis is more complex and CPU time is much more than that of quasi-3D analysis. The predicted pattern of flow behavior from full-3D and quasi-3D approaches is nearly the same. Hence, it is concluded that quasi-3D approach may be used to study the flow pattern in the turbine space and to obtain the best design by different combinations of the design parameters, turbine space and blade geometry and then this design can be analyzed by full-3D approach and finally assessed through model testing. This procedure will minimize time and money spent in development of new designs of turbines.
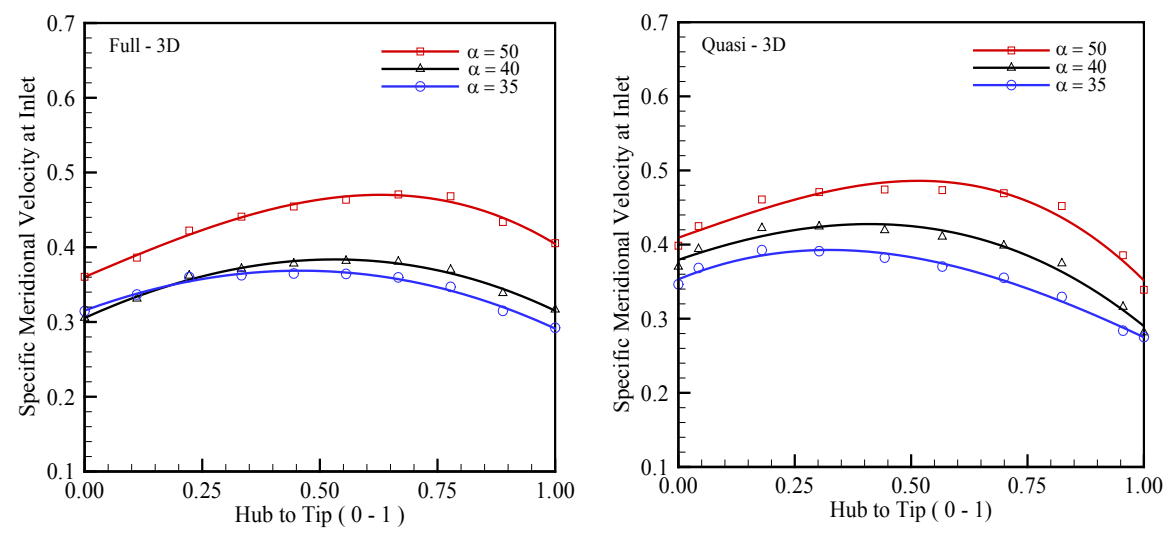

Fig.3-Span-wise variation of meridional velocity at runner inlet
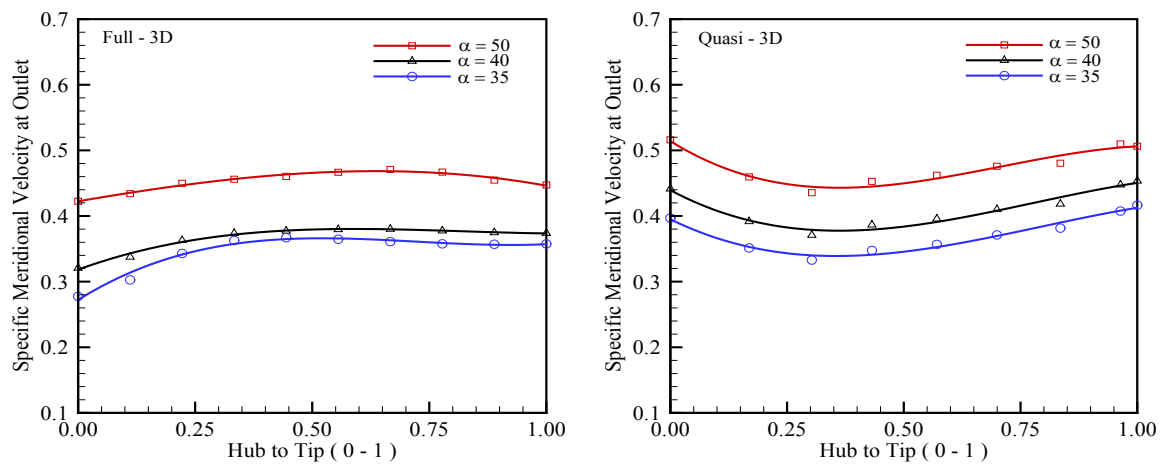

Fig.4- Span-wise variation of meridional velocity at runner outlet
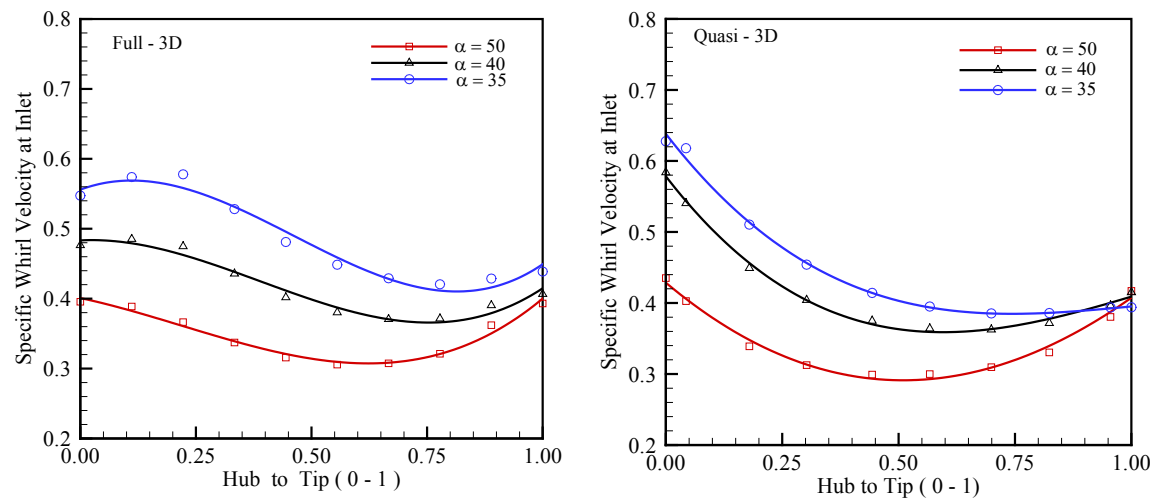

Fig. 5 - Span-wise variation of whirl velocity at runner inlet
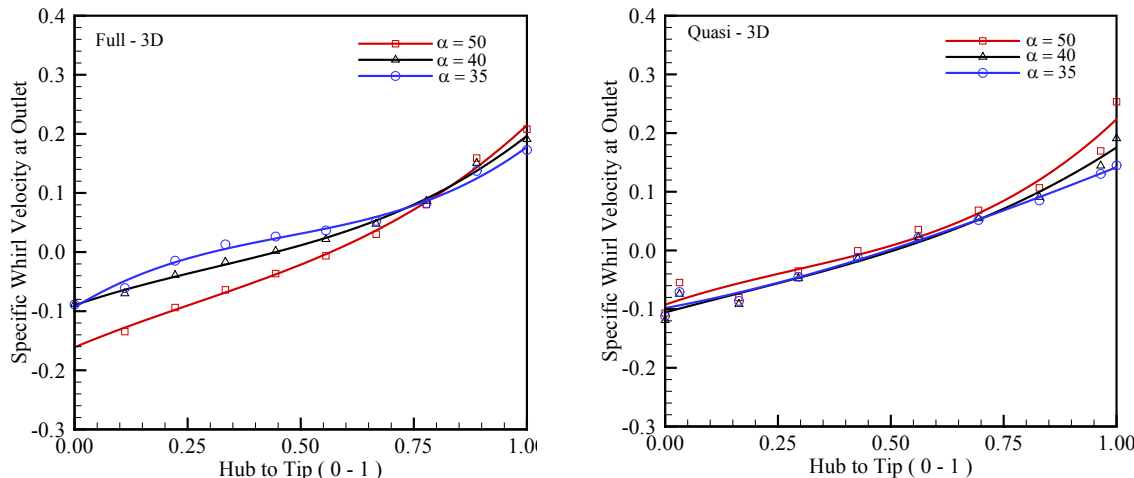

Fig. 6 - Span-wise variation of whirl velocity at runner outlet 

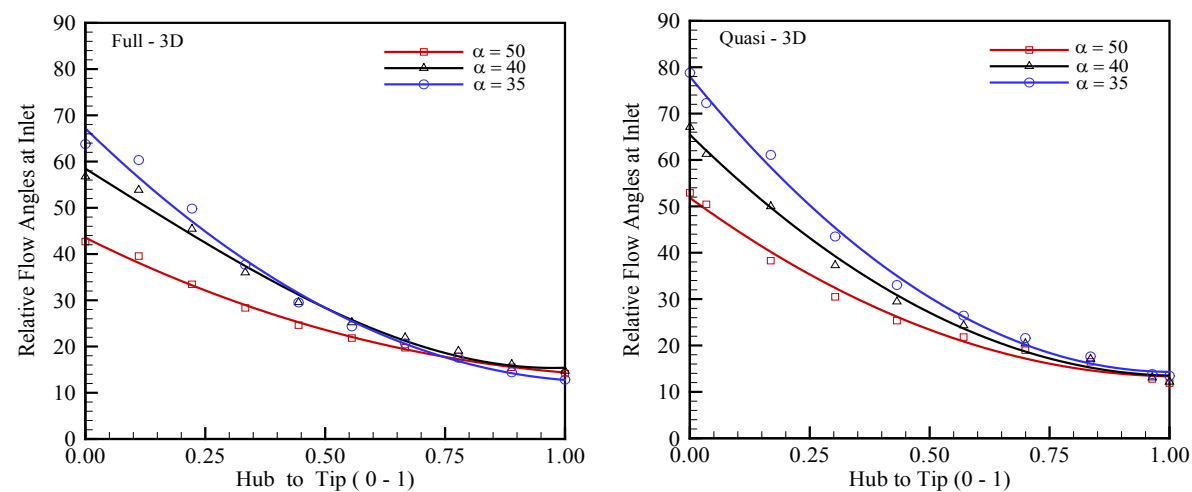

Fig. 7 - Span-wise variation of flow angles at runner inlet
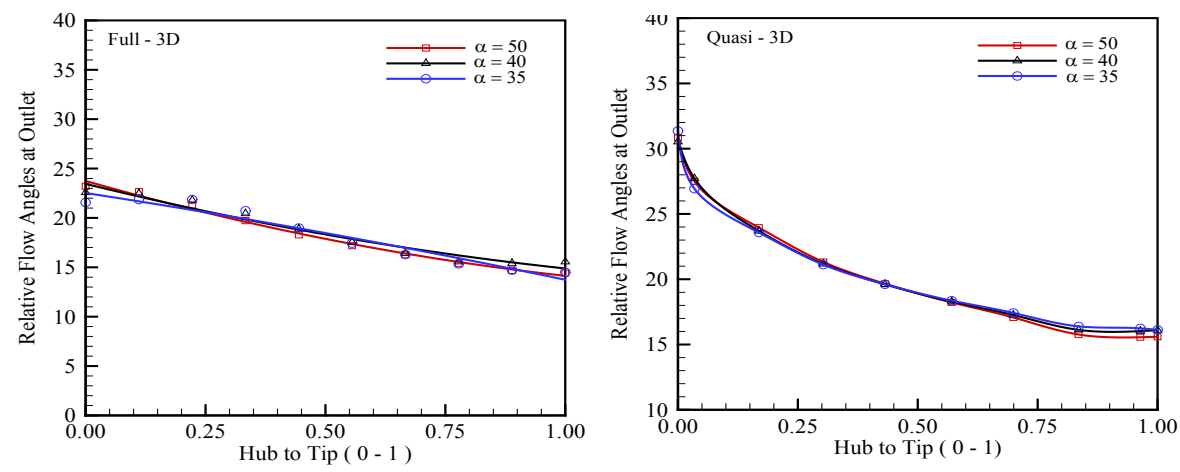

Fig. 8 - Span-wise variation of flow angles at runner outlet

\begin{tabular}{|l|l|l|l|l|l|l|}
\hline \multirow{2}{*}{} & \multicolumn{2}{|c|}{$\alpha=5^{\circ}$} & \multicolumn{2}{c|}{$\alpha=4^{\circ}$} & \multicolumn{2}{c|}{${ }^{\circ}=3^{\circ}$} \\
\cline { 2 - 7 } & full-3D & quasi-3D & full-3D & quasi-3D & full-3D & quasi-3D \\
\hline$c_{\mathrm{m} 1}$ & 0.459 & 0.452 & 0.395 & 0.396 & 0.343 & 0.362 \\
\hline$c_{\mathrm{m} 2}$ & 0.461 & 0.477 & 0.387 & 0.411 & 0.351 & 0.374 \\
\hline$c_{\mathrm{u} 1}$ & 0.338 & 0.329 & 0.419 & 0.389 & 0.475 & 0.425 \\
\hline$c_{\mathrm{u} 2}$ & 0.032 & 0.049 & 0.070 & 0.036 & 0.080 & 0.038 \\
\hline $\mathrm{w}_{1}$ & 1.257 & 1.268 & 0.935 & 0.959 & 0.784 & 0.820 \\
\hline $\mathrm{w}_{2}$ & 1.527 & 1.513 & 1.238 & 1.277 & 1.411 & 1.162 \\
\hline$c_{1}$ & 0.573 & 0.561 & 0.584 & 0.556 & 0.596 & 0.559 \\
\hline$c_{2}$ & 0.483 & 0.486 & 0.422 & 0.418 & 0.368 & 0.382 \\
\hline$\varepsilon$ & 5.579 & 4.490 & 9.640 & 9.850 & 15.590 & 13.940 \\
\hline$\varphi$ & 0.752 & 0.682 & 0.658 & 0.632 & 0.687 & 0.677 \\
\hline$\tau$ & 0.168 & 0.158 & 0.192 & 0.190 & 0.217 & 0.216 \\
\hline$\Psi$ & 5.406 & 5.289 & 7.753 & 7.288 & 9.329 & 8.740 \\
\hline
\end{tabular}

Table4: Comparison of computed average values of different parameters

Vishnu Prasad, M.Tech., Assistant Professor in Maulana Azad National Institute of Technology, Bhopal, India (MANIT) is presently pursuing research in hydraulic turbines and water resources. He has 17 years of experience in teaching, consultancy and research at Hydro Research Centre, MANIT. He had been to UK for training on model testing and CFD for six months. He has published 37 papers and guided 30 M.Tech dissertations.

Corresponding address :vpp7@yahoo.com

$\boldsymbol{P}$ Krishnamachar has been engaged in teaching, research, consultancy and developing technical institutions for the past 48 years at IIT, Kharagpur, EdF France, MANIT, University of Rutgers, USA etc. Specialized in Water Power and energy 
conservation, he has over 96 papers and two books published and presented at various forums. He is a Hydro consultant and is working on design of small hydro power plants as a member of Micro Hydel Core group of DST, India.

Corresponding address : pkrishnamachar@rediffmail.com

KS Sayann has been engaged in teaching, research and consultancy since 1974 at MANIT, Bhopal. Dr. Sayann has worked in various administrative positions including Director of MANIT and published many research papers.

Corresponding address : sayan_kss@yahoo.com

\section{References}

ANSYS, 2005, Ansys CFX1O.o Help Manual, Bangalore:ANSYS Software Pvt. Ltd.

Balint Daniel, Resiga-Susan Romeo and Muntean Sebastian, 2003, A numerical approach for the 3D flows in Kaplan turbine, in Proceedings of the International Conference on CSHSO3, Belgrade, pp.29-36.

Csanady, G.T., 1964, Theory of Turbo Machines, MacGraw-Hill Book Company, New York

Frank Kenyery, Robert Ray, Ricardo Noguera, 2002, Dimensioning and Performance Analysis of an Axial Flow
Hydraulic Turbine of High Power/Weight Ratio, TASK Quarterly 6, 4:609-620.

Guoyi Peng, Shuliang Cao, Masaru Ishizuka and Shinji Hayama, 2002, Design optimization of axial flow hydraulic turbine runner: Part II-multi-objective constrained optimization method, International Journal for Numerical Methods in Fluids, 44(2):533-548.

Guoyi Peng, 2005, A practical combined computation method of mean through-flow for $3 \mathrm{D}$ inverse design of hydraulic turbo machinery blades, Journal of Fluids Engineering, 127:11831190.

Lewis, R.I., 1996, Turbo machinery Performance Analysis, Arnold, London.

Liplej, A., 2004, Optimization method for the design of axial flow hydraulic turbines, Journal of Power \& Energy, 218(A):43-46.

Nechleba, M., 1957, Hydraulic Turbines-Their Design and Equipment, Artia Prague.

Rao, V. S. and Tripathi, S.K., 2007, Role of CFD analysis in hydraulic design optimization of hydro turbines, Proceeding of National Seminar on CFD-The $3^{\text {rd }}$ Dimension in Flow Analysis \& Thermal Design, RGPV, Bhopal, pp196-201. 